\title{
Laboreal
}

Volume 12 №2 | 2016

Equipamentos de Proteção Individual II

\section{O trabalho: uma conduta}

El trabajo: una conducta

Le travail: une conduite

The work: a conduct

\section{Régis Ouvrier-Bonnaz e Annie Weill-Fassina}

Tradutor. João Viana Jorge

\section{CpenEdition}

\section{Journals}

\section{Edição electrónica}

URL: http://journals.openedition.org/laboreal/2702

DOI: 10.4000/laboreal.2702

ISSN: 1646-5237

\section{Editora}

Universidade do Porto

\section{Refêrencia eletrónica}

Régis Ouvrier-Bonnaz e Annie Weill-Fassina, « O trabalho: uma conduta », Laboreal [Online], Volume 12 No2 | 2016, posto online no dia 01 dezembro 2016, consultado o 24 setembro 2020. URL : http:// journals.openedition.org/laboreal/2702 ; DOI : https://doi.org/10.4000/laboreal.2702

Este documento foi criado de forma automática no dia 24 setembro 2020.

Laboreal está licenciado com uma Licença Creative Commons - Atribuição-NãoComercial 4.0 Internacional. 


\title{
O trabalho: uma conduta
}

\author{
El trabajo: una conducta \\ Le travail: une conduite \\ The work: a conduct
}

Régis Ouvrier-Bonnaz e Annie Weill-Fassina

Tradução : João Viana Jorge

\section{NOTA DO EDITOR}

http://dx.doi.org/10.15667/laborealxii0216robpt

Manuscrito recebido em: maio/2016

Aceite após peritagem: setembro/2016

1 1. Ignace Meyerson nasceu em Varsóvia em 1888. Após a "insurreição russo-polaca de 1905"emigra para França onde se junta a seu tio, o filósofo e historiador das ciências, Émile Meyerson (1859-1933). Licenciado em filosofia, médico, interno dos hospitais psiquiátricos de Paris, consagra-se antes do mais à investigação em fisiologia. Nos anos 30 (do séc. XX) é reconhecido pelos seus trabalhos com Paul Guillaume sobre a utilização de instrumentos pelos macacos. Por instigação de Pierre Janet (1881-1947) é nomeado secretário e depois diretor, em 1938, do «Journal de Psychologie normal et pathologique», a qual com "L'année psychologique», então dirigida por Henri Piéron (1881-1964), delimita a paisagem da psicologia francesa da primeira parte do séc. XX. Meyerson e Henri Piéron têm uma conceção diferente da psicologia: por um lado uma conceção histórico-cultural baseada na observação e objetivação das variações e produções humanas em meio natural e das suas evoluções no decurso do tempo, e por outro uma conceção experimental e positivista baseada no estudo de funções de natureza biológica (que eram) supostas responderem a leis imutáveis. Em 1953 criou, no seio da VIa secção da Ecole Pratique des Hautes Études, o Centre de Recherches de Psychologie comparative. Meyerson foi considerado como o fundador da psicologia histórica, 
objetiva e comparada, desenvolvida por Philippe Malrieu em França e Jerome Bruner nos países anglo-saxónicos [1].

2 2. O texto aqui apresentado insere-se num momento particular da história de Meyerson. Proibido de ensinar a 19 de dezembro de 1940 devido às leis raciais em vigor durante a segunda guerra, depois expulso da Cátedra de psicologia que ocupava na Faculdade de letras de Toulouse onde se tinha refugiado, funda a Société d'Études Psychologiques em maio de 1941 a fim «de tentar abranger o melhor possivel a plenitude das condutas, especialmente dos atos, das tarefas e das obras complexas do homem e a partir daí compreender o homem total» (1948, p. 7). Afirma assim a sua proximidade com o sociólogo Marcel Mauss (1872-1950) quando este, dirigindo-se aos psicólogos em 1924 na altura da sua eleição para a presidência da Société Française de Psychologie, determina que é sempre o homem completo que temos de ter em conta.

Neste período difícil envolve-se numa pesquisa sobre o que pressiona o homem a agir, a partir da sua experiência pessoal, para compreender o que ele designa de «homemação». A criação da Société d'Études psychologiques permite-lhe retomar contacto com a ação intelectual e científica. Pouco tempo depois compromete-se com a Resistência contra o nazismo. Com Meyerson, como especifica Jean-Pierre Vernant, aluno seu que se inspirará na psicologia histórica para elaborar uma antropologia da Grécia antiga, estas duas formas de compromisso constituem um todo que lhe proporciona a oportunidade de prosseguir a sua reflexão sobre a possibilidade de estudar uma " história da vontade» e em particular melhor compreender o lugar do outro na " recuperação e no acréscimo das forças pessoais de um indivíduo». Vernant, depois de ter estudado dois documentos inéditos deste período resume a interrogação de Meyerson: "Que significa esta necessária presença do outro na consolidação da firmeza própria e do seu querer? Em quê, o ato positivo, o dom, o que recebemos do outro ou the oferecemos, pode constituir uma dimensão maior de uma genética da vontade?» (1996, p. 48).

4 3. Le travai: une conduite, datado de 1941 e publicado em 1948 é o prefácio de uma publicação, Le Travail et les Techniques, que agrupa as comunicações apresentadas por ocasião da Journée de Psychologie et d'Histoire du Travail et des Techniques, organizada por Meyerson a 23 de Junho de 1941, em Toulouse, no quadro da sua "Societé" [2]. Este texto encontrará o seu prolongamento no pós guerra, em dois outros textos com os quais estabeleceremos a ligação.

$5 \quad$ 3.1. O prefácio é constituído por duas partes.

6 3.1.1 Uma primeira parte (p. 7-11) retrata a génese da jornada de 23 de Junho. Aí Meyerson determina que essa Jornada se inscreve plenamente no programa da Sociedade: "O esforço científico em psicologia abre hoje um largo espaço às pesquisas comparadas. 0 estudo das condutas, dos sentimentos, do pensamento, apoia-se cada vez mais no concreto. Aplica-se na análise dos produtos da atividade, do pensamento humano, da história natural e social do homem e também da dos animais, vistas através de um número tão grande quanto possivel de manifestações. Estas pesquisas, cujos resultados se consideram importantes implicam a convergência de técnicas diversas: o psicólogo deve apelar ao contributo dos antropólogos, dos etnólogos, dos geógrafos; dos linguistas e dos filólogos; dos historiadores e dos historiadores das letras, das artes, das religiões; dos juristas tanto quanto à de, mais antecipadamente adquirida, dos filósofos, dos biólogos, dos físicos (1948, p. 8). Para Meyerson a compreensão da historicidade das categorias mentais e das funções psicológicas releva necessariamente de uma abordagem pluridisciplinar. Na peugada do psicólogo Henri Wallon (1879-1962) e dos fundadores dos Annales d'histoire économique et sociale em 
1929, dos historiadores Marc Bloch (1886-1944) e Lucien Febvre, introduz o ponto de vista histórico em psicologia, consequentemente com a necessidade do trabalho interdisciplinar. Para Roger Chartier é «esta historicidade essencial dos objetos da psicologia que autoriza a defini-la como uma antropologia histórica» (1996, p. 232) o que permite opor à ideia de uma percepção imediata, existencial, fenomenológica, das categorias mentais e psicológicas, defendida na mesma época pelo filósofo Jean-Paul Sartre, o seu conhecimento a partir de formas simbólicas e de factos históricos nos quais são objetivadas. Por ocasião de um colóquio mantido em 1960. Problèmes de la personne (1973), Meyerson pormenoriza o que coloca na base desta perspetiva de pesquisa: «a história que aqui tentámos é uma antropologia histórica, qualquer coisa como a história do homem interior correspondente à história do homem exterior, do homem social, à história das civilizações e dos factos da civilização; há correspondência entre as duas, elas não são paralelas. As funções psicológicas têm uma história e tomaram formas diversas através dessa história. $O$ tempo, a memória, têm uma história. O espaço tem uma história. A pessoa tem uma história» (1973, p. 474).

7 3.1.2 Na segunda parte (p. 12-16) do preâmbulo, Meyerson esforça-se por mostrar que esta postura epistemológica se aplica ao trabalho. Ali resume a exposição introdutória produzida nas duas sessões de estudo que precederam a Jornada de 23 de Junho de 1941. Para ele «há uma história, uma carreira psicológica da ideia de trabalho» (1948, p. 15). 0 estudo do trabalho que permitirá escrever essa história é ainda «fragmentário $e$ disperso» e «a história das primeiras formas da técnica é muito mal conhecida», de onde a necessidade de continuar a constituí-la. Meyerson lembra o papel que os fisiologistas desempenharam no estudo do esforço muscular e da fadiga mas também, globalmente do motor humano para pensar nas variações individuais na realização das tarefas e refletir nas condições de exercício dos ofícios.

8 Aqueles últimos e os psicólogos puderam assim «mostrar que o sistema Taylor e seus derivados analisaram e compreenderam mal o trabalho. 0 homem no trabalho não é apenas a soma de movimentos e de tempos parcelares e o homem não é apenas o homem no trabalho. $O$ que escapa ao cronómetro, no todo ou em parte não é menos importante do que o que é medido" (idem, p. 12-13). Para Meyerson é necessário interessarmo-nos pelo «homem total», o que a psicotécnica tentou em parte fazer interessando-se mais pelo fator humano (idem, p. 14). Em conclusão, ele apresenta uma primeira definição: o trabalho não é encarado sob o ângulo da técnica mas como uma conduta da qual é preciso procurar as componentes e as camadas de significação. «É ao mesmo tempo uma atividade forçada, uma ação organizada e contínua, um esforço produtivo, uma atividade criativa de objetos e de valores possuindo uma utilidade para um (dado) grupo, uma conduta cuja motivação pode ser pessoal (...) mas cujo efeito diz respeito aos outros homens» (idem, p. 16). Encontra-se no caracter constrangedor da atividade de trabalho a abordagem de Wallon quando precisa, desde 1930, que «o trabalho é uma atividade forçada ... O seu objeto mantém-se estranho às nossas necessidades, mais ou menos imediatas, e consiste no cumprimento de tarefas que não estão necessariamente de acordo com o jogo espontâneo das funções físicas e mentais» (1930, p. 11).

9 4. O trabalho: uma conduta, é, como dito, o primeiro de uma série de três textos onde Meyerson desenvolve a sua reflexão sobre o trabalho em coerência com a sua tese apresentada em 1947, e publicada em 1948, Les fonctions psychologiques et les oeuvres.

10 4.1. No segundo texto desta série - Comportement, travail, expérience, obra - publicada em 1951 em L'année psychologique, foi discutida a ideia de que o trabalho é o próprio 
comportamento humano - a análise do efeito da ação humana sobre o mundo permitindo compreender o homem. Mais precisamente, é através das realizações concretas e das relações tecidas entre os homens para levar a cabo essas realizações que o homem se forma e se transforma; de onde esta definição do trabalho como atividade cumprida, incarnada no produto dessa atividade (a obra) e o que foi investido em força física e psíquica para aí chegar. A obra é, tudo em simultâneo, o produto da conduta, do trabalho e da experiência, «o comportamento não pode compreender-se sem a obra e em consequência o exame das obras, longe de se desvelar apenas ao historiador, deve constituir a matéria principal da pesquisa do psicólogo» (1951/1987, p. 69). Neste artigo Meyerson afina a sua definição de trabalho como «ação sistematizada, organizada com vista a (obter) um efeito produtivo, produzida em comum pelos homens e destinada a criar objetos e valores com utilidade para um (dado) grupo (...) é além disso uma atividade disciplinada submetida aos constrangimentos da matéria e do meio humano» (idem, p. 67).

11 4.2. No terceiro texto, Le travail, fonction psychologique, publicado em 1955 no Journal de psychologie normal et pathologique, Meyerson retoma, para a completar, a definição de trabalho exposta nos dois textos precedentes insistindo sobre o seu carácter sempre dirigido, «o trabalho é uma atividade que tem por finalidade transformar a matéria e produzir, criar objetos ou valores úteis para um grupo humano ou desejados por esse grupo; que pode ter motivações variáveis e complexas: lucro, ambição, gosto, prazer, diversão, dever, constrangimento; mas cujo efeito diz sempre respeito diretamente a outros homens e é sentido como tal por aquele que produz e por aqueles que consumirão o produto» (1955-1987, p. 252). Para assentar a sua definição e esclarecer o seu próprio ponto de vista retoma a história da noção de trabalho esboçada no texto de 1941 e apoia-se nas contribuições de Alexandre de Laborde, Saint-Simon, Fourier, Proudhon, Marx: «Vejamos a história técnica do trabalho ... Contrapartida das transformações da civilização material, segue a história das invenções, dos instrumentos, das máquinas, das indústrias, está ligada ao ritmo das invenções e das suas aplicações ... : qualquer técnica nova tem como fonte e como acompanhamento uma novidade mental e qualquer invenção pouco importante reage por sua vez sobre o homem, sobre o espírito» (idem, p. 253). Nesta história retém uma conclusão de pesadas consequências para a psicologia referente ao que designa «o humanismo trabalhista» de Proudhon (1858): «Se o trabalho é a atividade primária, as outras atividades do homem derivam daí. $\mathrm{E}$ acrescenta, «é preciso dizer não apenas que o pensamento provém da ação mas: todo o conhecimento provém do trabalho» (idem, p. 258).

12 Meyerson assinala, tendo em vista a evolução das formas de produção do trabalho, que "para que o trabalho possa aparecer como uma função una e independente... foi preciso que o homem tenha sido, em grande parte, dela desligado. ... Quando a máquina substituiu o homem em muito grande parte, quando fazia o que ele fazia e até mais, quando a viu funcionar quase só, o homem olhou e viu o trabalho, pôde objetivá-lo, aperceber-se do aspeto sistematizado $e$ diferenciado, pensá-lo como tal» (idem, p. 261). No final desta evolução, «o trabalho entrou na pessoa e tende a lá ocupar um grande lugar» (idem, p. 262).

13 5. Para Meyerson, nota-se nestes três textos, o trabalho é historicamente constituído. $O$ trabalho estudado durante um período longo permite constituí-lo como um facto social no sentido que Durkheim (1895) atribui a esse termo, "apresenta-se-nos como uma das principais atividades das sociedades humanas, talvez como a principal, como a base da sociedade $»$ (idem, p. 252). 


\section{é e tem uma função psicológica, é criado pelo homem e em retorno age sobre ele. A} função do trabalho tem assim uma dupla vida:

15 - O trabalho é uma função psicológica enquanto produtor de objetos, de serviços à disposição da sociedade e produtor de intercâmbios sociais que lhes atribuem o seu valor nessa sociedade. Cumpre-se por e para a sociedade;

16 desenvolvimento dos sujeitos ou, pelo contrário, ser um constrangimento improdutivo para a sua atividade, até um constrangimento deletério se os sujeitos não são colocados em situação de dele se apropriar para o tornar um recurso.

É importante discernir bem esta dupla função do trabalho. Encarada sob este duplo aspeto permite, com efeito, colocar a questão da subjetividade nas atividades de trabalho: os atos humanos passando em geral por uma procura de significados pondo em jogo a experiência dos sujeitos. O homem transforma e é transformado pela experiência.

No texto Le travail: une conduite, Meyerson defende a ideia da possível existência de uma psicologia histórica em ligação com a história do trabalho. Para ele, como o indica desde o prefácio do seu livro, As funções psicológicas e as obras, «os atos do homem finalizam em instituições e em obras. ...O espírito do homem reside nas obras... A ação, o pensamento humano exprimem-se pela sua obra. O espírito não se exerce no vazio; não é e não se reconhece senão no seu trabalho, nas suas manifestações dirigidas, expressas, conservadas» (1948, pp. 9-10). O uso que Meyerson faz da obra reenvia amplamente para toda a realização humana, todo o resultado de um trabalho. Para Françoise Parot $(1996$, p. 2) trata-se de construir um saber relativo ao psiquismo humano que seja «um saber fundado no estudo minucioso das suas produções, de todas as suas produções aqui e agora mas também aqui e além ». É ao estudar o efeito da ação humana sobre o mundo que se podem compreender as funções psicológicas constitutivas da pessoa e do seu desenvolvimento. A ideia de construção predomina, «por todas as suas condutas o homem é construtor» $(1948$, p. 28). Nas condutas humanas, os atos são sistemáticos, são submetidos a convenções e normas, têm uma forma, um significado» (idem, p. 16). A noção de atividade desenvolvida na ergonomia francófona e em psicologia do trabalho encontra uma das suas fontes nesta ideia de conduta.

6. A conclusão do texto, Le travail: une conduite, lembra-nos insistentemente: a psicologia do trabalho muda com o próprio trabalho, de onde a importância de adotar um ponto de vista histórico para compreender o modo como o trabalho aparece como «função psicológica que se forma num dado momento e que se transforma divergindo a seguir» (1948, $\mathrm{p}$. 16). «A contribuição do histórico para o estudo do humano» permite afastar «a pressuposição de categorias eternas, ao mesmo tempo que coloca a tónica nos problemas do encaminhamento das mutações e dos progressos (ou eventualmente dos recuos)» colocando à distância «a explicação redutora pelo mais elementar, pelo mais simples» (1954, p. 9). Desde então, incumbe aos investigadores e aos profissionais estarem atentos às evoluções do mundo do trabalho para manter a ligação com as realidades do seu tempo. Num período em que a modificação das relações sociais de produção guiadas pela procura exclusiva do lucro em detrimento da iniciativa individual e coletiva ameaça cada vez mais para o homem a compreensão do sentido dos seus atos e do seu alcance, os textos de Meyerson deveriam constituir para isso uma ajuda. 


\section{BIBLIOGRAFIA}

Bruner, J. (1996). L'éducation, entrée dans la culture. Paris : Retz.

Chartier, R. (1996). Lire Meyerson aujourd'hui. Dans Pour une psychologie historique. Ecrits en hommage à Ignace Meyerson (pp. 232-235). Paris : PUF.

Clot, Y. (1999). La fonction psychologique du travail (Préface de la troisième édition). Paris: PUF. Durkheim, E. (1895). Les règles de la méthode sociologique. Revue philosophique. Edition 2009.Paris : Payot.

Meyerson, I. (1948/1955). Les fonctions psychologiques et les œuvres. Paris : Librairie philosophique J. Vrin. Republié en 1955. Paris : Albin Michel.

Meyerson, I. (1951). Comportement, travail, expérience, œuvre. L'Année psychologique, 77-82. Repris dans Ecrits. 1920-1983. Pour une psychologie historique, 66-70.

Meyerson, I. (1954). Thèmes nouveaux de psychologie objective : l'histoire, la construction, la structure. Journal de psychologie normale et pathologique, 1-2, 3-19.

Meyerson, I. (1955). Le travail, fonction psychologique. Journal de Psychologie, LII, 3-17. Repris dans Ecrits. 1920-1983. Pour une psychologie historique, 253-263.

Meyerson, I. (1973). La personne et son histoire. I Problèmes de la personne (pp. 473-482). ParisLa Haye : Mouton \& Co.

Parot, F. (1996). Présentation. In Pour une psychologie historique. Ecrits en hommage à Ignace Meyerson (pp. 1-5). Paris : PUF.

Proudhon (1858/1932). Travail. In De la Justice dans la Révolution et dans l'Eglise. CEuvres complètes, VIII, 3. Paris : Ed. Bouglé-Moysset.

Vernant, J.-P. (1996). Deux inédits retrouvés dans les archives : « Il doit y avoir une histoire de la volonté ». In Pour une psychologie historique. Ecrits en hommage à Ignace Meyerson (pp. 47-59). Paris : PUF.

Wallon, H. (1930). Principes de psychologie appliquée. Paris : Armand Colin.

\section{NOTAS}

1. Ver, no que respeita a Jerome Bruner, L'éducation, entrée dans la culture: «Negligenciaram-se durante demasiado tempo as vantagens da externalização em obra das realizações concretas de qualquer atividade cultural, não apenas das obras oficialmente reconhecidas mas (também) das obras coletivas que simultaneamente criam e mantêm a solidariedade de grupo» (1996, p. 39).

2. A obra «Le Travail et les Techniques» foi publicada pela editora Presses Universitaires de France (PUF) em 1948, sete anos após o decurso da jornada de 23 de Junho de 1941. Pode admitirse razoavelmente a hipótese de que Meyerson introduziu na sua apresentação escrita elementos mais de acordo com a evolução das suas pesquisas - elementos que não figuravam na sua apresentação oral de 1941. Esta obra foi também apresentada por Catherine Teiger num artigo incluído na Laboreal, Vol. XI, 2 (2015): L'alliance théorie/pratique dans l'ouvrage du sociologue du travail Georges Friedmann (1922-1977). 


\section{AUTORES}

\section{ANNIE WEILL-FASSINA}

Groupe de Recherches sur l'Histoire du Travail et de l'Orientation (GRESHTO)

Centre d'Études sur le travail et le développement (CRTD)

Centre National des Arts et Métiers (CNAM), 41 Rue Gay-Lussac, 75020 Paris, France

regis.ouvrier_bonnaz@cnam.fr

weill.fassina@orange.fr 